\title{
1. An introduction to the economic issues involved in sustaining biodiversity and ecosystem functions
}

\subsection{WHY THIS SUBJECT IS IMPORTANT}

Both the stock of the world's biological diversity and the state of its ecosystems are major influences on the ability of humankind to sustain and increase its well-being. They are major determinants of the availability of commodities essential to human life, such as food and water, and they are also, to a large extent, interdependent. However, it is not only the supply of necessities which is affected by the state of biodiversity and ecosystems. Also the availability of many non-essentials that add to the quality of human life is directly or indirectly dependent on the state of biodiversity and ecosystems. Human societies are embedded in ecological systems which they have been altering for many millennia.

Even before agriculture commenced about 9000 years ago, humans were both altering natural ecosystems to increase their well-being and adapting their economic activities to varied local and environmental conditions. These processes gathered considerable momentum following the commencement of agriculture and its geographical spread. Major acceleration occurred in humankind's ability to control ('and conquer') nature following the Industrial Revolution, which began in Europe: processes set in motion by this revolution (mainly increasing reliance on the application of advances in science and technology and associated capital accumulation for achieving economic growth) have (and continue to have) major impact on the state of the globe's biodiversity and ecosystems.

A feature of this long-term development process has been the increased decoupling of human economic activity from its surrounding local environmental conditions. This has not only been made possible by advances in science and technology and capital accumulation but also by the development of market systems and their extension. This 'increased decoupling' is a major cause of losses of pre-existing biodiversity and the reduced presence of ecosystems that once existed. In effect, humankind now has to adapt its economic activities less to local environments than in earlier 
times. This is because it alters local environments or it is able to a significant extent to insulate its activities from them, on a scale which could never have been imagined by its forebears. Although this has added greatly to human well-being, it is unclear for how long this type of development process can continue to add to human well-being, given global population growth and increasing demands on the earth's biological resources and ecosystems.

The world's human population is expected to increase by a large amount between now and 2060. At the same time, the number of people with higher incomes demanding more food, especially more animal protein, is predicted to rise considerably. Even if the globe's level of population stabilizes around 2060, increased human demands on the earth's biological resources (as well as its non-reproducing, non-renewed resources) may well increase. Consequently, continuing global economic growth presents increased challenges for conserving wild biodiversity and natural ecosystems.

However, it is not only the conservation of wild biodiversity and natural ecosystems which are being threatened by continuing economic growth and its nature. A further casualty is the loss of heritage germplasm (developed in the past by humans) for the production of food, fibres and other biological products. As well, previously available ecosystems developed by humans for biological production are being lost. While keeping all of these heritage-types of capital is unlikely to be rational, their potential economic value should not be overlooked.

They are not a part of natural capital but they have many of the qualities associated with biological types of natural capital. For example, it is likely to be impossible (or virtually impossible) to replace most heritage germplasm once it is lost. Many contemporary studies of the economics of biodiversity conservation and ecosystems fail to pay attention (or adequate attention) to the importance of biological heritage capital for the maintenance of human well-being and focus entirely (or almost so) on natural capital. This is, in my view, an erroneous approach. Therefore, in this book considerable attention (but not exclusive attention) is given to the conservation of biological heritage capital as a contribution to human well-being and its sustainability. Attention is also given to reasons why this resource is being lost, and like natural capital, is being lost in ways that reduce human welfare or prospects for its sustainability.

It might be noted that heritage biological capital is just one type of heritage capital. Another is the stock of human knowledge. It is possible for at least parts of this knowledge to be irretrievably lost, with potential negative consequences for the future welfare of humanity.

This book grapples with all the above-mentioned issues. Part I (which includes this chapter) provides a general conceptual backdrop to 
contemporary debate about these issues. Part II concentrates on changes in human developed germplasm and sustainability issues involving human developed ecosystems. The focus in Part III is on the economics of conserving wild biodiversity and assessing the economics of the utilization of natural ecosystems and the supply of wanted ecosystem services. More detailed information about the coverage of this book follows.

\subsection{AN OVERVIEW OF THE REMAINDER OF PART I: BASIC ISSUES}

In order to assess the economic value of sustaining the existing stock of biodiversity and ecosystems, it is important to classify appropriately this stock and changes to it. One of the main objectives of Chapter 2 is to do this. It is argued in this chapter that most recent economic studies of this subject have failed to pay enough attention to the nature of changes in the basic composition of biodiversity and in the attributes of ecosystems. They have failed to give enough attention to human developed germplasm and ecosystems because they have concentrated almost exclusively on the value of natural biodiversity and natural ecosystems as a part of natural capital. As a result, insufficient attention has been given to the economics of trade-offs between conserving wild biodiversity and natural ecosystems and the impacts of human development of new germplasm and the overall consequences of human alterations to ecosystems. Consequently, there are major deficiencies in much contemporary economic analysis of the net benefits of conserving wild biodiversity and natural ecosystems.

Furthermore, there appears to be a tendency in much of the recent economic literature on the valuation of biodiversity and ecosystems to take account only of the positive contributions of wild biodiversity and natural ecosystems to human well-being. While this may be justified from the political perspective that most members of the general public undervalue the services provided by wild biodiversity and natural ecosystems, it is not a balanced perspective from a scientific point of view. It is pointed out in Chapter 2 that natural ecosystems (or some of their attributes) can be either assets or liabilities from a human perspective and that some wild organisms may be pests or assets. Balanced evaluation of changes to biodiversity and natural ecosystems requires all these aspects to be taken into account.

In assessing changes to biodiversity and ecosystems, we need to give attention not only to losses of wild biodiversity and natural ecosystems but also to losses in heritage (human developed) germplasm and human developed ecosystems. The latter losses are neglected in some recent influential 
studies (for example, Kumar, 2010) of the economics of biodiversity and ecosystem services. Socio-economic developments are the main drivers of these losses in the modern era. Socio-economic processes involved in transforming the genetic stock and altering ecosystems are identified in Chapter 3. It provides a general introduction to this subject.

In Chapter 3, the geographical extension of human contact and human migration are identified as important sources of alterations to the global genetic stock and to ecosystems. Their influence has been present for millennia. However, following the European Age of Discovery, these influences became a global phenomenon. In this chapter also ways in which capital accumulation and advances in science and technology have brought about changes in biodiversity and ecosystems are outlined. Furthermore, it is indicated how the development of market systems and their extension have been significant drivers of biodiversity loss and changes in ecosystem. Other institutional influences which are considered are the preference of supermarkets and fast food outlets for standardized products, the granting of property rights in new genetic material and the operations of political structures and special interest groups. Additional factors which are taken into account include increased labour mobility, the growth of large organizations, such as public companies, government failure to reduce open access to natural resources in a timely manner and path dependence in the human development of germplasm and ecosystems. In later chapters, more detailed consideration is given to most of the above relationships.

The above influences on changes in biodiversity and in the nature of ecosystems have implications for the sustainability of economic development. Sustainable development and changes in the genetic stock and ecosystems is the subject of Chapter 4. First, several general concepts of economic development are identified. Several of these contemporary criteria are inconsistent in the types of development paths that they favour. All these sustainable criteria are normative and in some cases they result in indeterminacy and in choices that are Paretian inferior. An alternative possible criterion based on safety first is suggested. Current welfare criteria for achieving sustainable development are very hypothetical. It is argued that it would be worthwhile giving greater attention empirically to determining the degree of concern which current generations show (as well as express) for the welfare of future generations. This would give empirical substance to an idea raised by David Pearce (1998, p. 71) and also considered by Herman Daly (1999, pp.115-16). This is likely to be more productive than concentrating only on the theoretical consideration of this subject.

There is no guarantee that any of the welfare criteria suggested for sustainable development will be able to be met. Humanity may not be willing to make sufficient economic sacrifices and to curb its population growth 
to achieve any of these objectives. Gowdy and Krall (2013), for example, warn that modern societies are in danger of becoming trapped in a system of ultrasociality in which they engage in mindless economic accumulation and population growth, like some species of ants.

Different views have been expressed about the conditions which need to be satisfied for achieving sustainable economic development. On the one hand, probably most mainstream economists believe that only weak conditions need to be imposed on the utilization of natural resources, including biological resources, to achieve sustainable economic development. Politically this is a popular view. On the other hand, most ecological economists suggest that strong conditions on the use of natural resources would need to be imposed to achieve sustainable economic development. These opposing views are discussed.

Uncertainty about the future makes it difficult to plan for sustainable development. Some of the problems that arise are discussed and particular attention is given to the precautionary principle. It is shown that, contrary to common belief, this principle does not always favour the conservation of natural resources, including the conservation of biodiversity.

A more specific sustainability issue, which is discussed from a general perspective in this chapter, is the sustainability of agroecosystems. Its focus is on ideas which were originally suggested by Gordon Conway (1985; 1987). This analysis is given further attention in Chapter 8 , which examines the economic value of human developed and modified ecosystems from a general perspective. However, all the chapters in Part II raise issues which are relevant to agricultural sustainability and to other bio-industries.

\subsection{AN OVERVIEW OF PART II - HUMAN DEVELOPED GERMPLASM AND ECOSYSTEMS - ECONOMIC ANALYSIS OF ISSUES INVOLVED IN BIOLOGICAL CONSERVATION}

Chapter 5 discusses socio-economic factors that have influenced the development of crop varieties (mostly food crops) and their consequential impacts on biodiversity loss and change. Socio-economic factors which have resulted in the loss of food crop germplasm include changes in the demand for different types of food, such as increased demand for prepared and ready-to-eat food, and alterations in the nature of the food chain. This chain has become longer and institutional developments have transformed it, for example, the evolution of supermarket chains and large food processors. An additional influence on biodiversity change has been an increase in the number of end uses of particular types of crops. For example, some 
crops are used now not only to feed humans but to feed livestock and produce biofuel, as well as other end products.

On the supply side, the arrival of new species or varieties of food crops often results in loss of biodiversity present in existing crops. This is discussed and examples are given. Additional influences on biodiversity loss in crops include improved methods and reduced costs of transporting produce (as well as easier availability of off-farm inputs). New methods for harvesting crops and the development of new post-harvest technologies have also had an influence. Various technological and market developments have also resulted in the monoculture of crops replacing polyculture, for economic reasons. This is discussed. The increased adoption of monoculture contributes to the loss of pre-existing crop biodiversity.

Market extension (made possible both by technological and scientific advances and by institutional changes) has been a major force for altering the global stock of biodiversity. It has altered the geographical pattern of the composition of biodiversity and has contributed to biodiversity loss. This is a result of increased regional economic specialization in production. As pointed out in Chapter 5, this is not only due to increased regional specialization in the supply of end products but is also facilitated by greater international and inter-regional trade in agricultural inputs. It is found that the overall impact of increased (economic) globalization is to reduce global biodiversity, particularly the diversity of existing germplasm.

Because of the socially dominating structure of modern (market) economies (their ultrasociality?) the political dictates of economic growth make it difficult (virtually impossible) to avoid continuing loss of global biodiversity for reasons which are discussed. Furthermore, as a result of the large anticipated increase in global population and rising per capita income in this century (for example, the continuing emergence of a sizeable middle class in Asia), global demand for food (especially animal protein) is expected to increase substantially. It is unlikely that this demand will be met without further biodiversity loss. In the light of this prospect, two divergent views have emerged about how to respond to it in order to minimize environmental costs, including the loss of biodiversity. One view favours a land-saving (land-sparing) approach involving the intensification of production by bio-industries, including agriculture. The other favours a land-sharing (mixed land-use) approach which would result in extension of land use by agriculture and other bio-industries. These views are discussed. They also receive further attention later in this book.

The economics of conserving the germplasm of crops has been given little attention by economists probably because it is a difficult topic requiring considerable interdisciplinary cooperation. Some economic factors which are relevant to deciding on the desirability of conserving this 
germplasm are explored. These factors include the nature of demand for different types of food crops (the level and elasticities of demand for them), the extent to which livelihoods and income depend on particular crops, and anticipated changes in environmental conditions, including climate change. Consideration is given to the economics of conserving food crops by adopting different methods, such as their conservation in seed banks, in situ and ex situ or on state farms and research stations.

Chapter 6 concentrates on the identification of socio-economic factors that have contributed to the loss of genetic diversity of domesticated animals, particularly livestock. It complements the discussion in Chapter 5 because most of the socio-economic factors that have contributed to biodiversity loss in food crops have also contributed to loss of livestock biodiversity. It provides additional economic analysis which is relevant not only to understanding the causes of biodiversity loss in livestock but which throws further light on the reasons for a decline in crop biodiversity. In addition, it examines several other issues related to livestock husbandry such as its environmental consequences and its impact on food security.

In this chapter, the proximate causes of the loss of livestock breeds and the various socio-economic (and other) processes that have contributed to this are identified and analysed. Particular attention is given to the Swanson dominance-effect, the consequences of market extension and economic globalization, loss of multi-purpose breeds of livestock, and the impact on the diversity of breeds of the increased decoupling of animal husbandry from local environments. The disappearance of local breeds of pigs in Vietnam provides a short illustrative case study. This case study is followed by a discussion of the consequences of the development of livestock husbandry for the loss of wild biodiversity. Taking Australia as an example, it is pointed out that some Australian wild species have benefited from pastoralism but others have been endangered or have become extinct as a result of it. The net effect of pastoral activities has been to reduce global wild biodiversity. The impacts of livestock husbandry on food security are discussed. It is argued that, in various circumstances, the keeping of livestock adds to human food security and food supplies, even though there are situations in which it reduces the amount of food available for human consumption. It is usually the latter case that obtains coverage in the literature discussing this matter, rather than the former possibility. Both aspects are considered in this chapter.

In recent decades, genetic engineering has opened up new possibilities for altering biodiversity and for changing the way in which ecosystems are used. Species from several biological kingdoms (for example, bacteria, plants and animals) have been genetically modified. However, Chapter 7 concentrates mainly on the genetic modifications of crops (plants) and 
examines its ecological and economic consequences. Both are considered because economic assessments of the value of transgenic crops require their ecological effects to be taken into account. Various types of attributes which had been imparted to crops by genetic engineering are identified and then consideration is given to the ecological processes involved in biodiversity loss as a result of the use of genetically modified (GM) crops.

Subsequently, it is pointed out that trade-off of attributes and erosion of biological fitness problems usually occur after a GMO (genetically modified organism) comes into use (and some examples are given). When a particular organism is genetically modified to increase its biological fitness for a particular purpose, some of its other desirable attributes may be weakened or may become negative. It is even possible for the overall fitness of genetically modified organisms to decline both from a biological and an economic point of view. Furthermore, when crops are engineered to resist particular pests, this may provide a niche for populations of non-targeted pests to increase. The effectiveness of the genetic modification in controlling pests of the genetically modified crops can be expected to decline with the passage of time. Continuing effectiveness is likely to require increasingly more 'powerful' genetic modification. Some measures which can be adopted to counteract biological erosion in the biological fitness of a genetically modified crop are discussed.

The release of GMOs involves considerable environmental risk and uncertainty. Therefore, as discussed, consideration has to be given to how much caution should be exercised before releasing a GMO, the appropriate social criterion to apply when considering the release of a GMO, and the legal liability that ought to be placed on suppliers and on adopters of GMOs for any unwanted consequences of its use. These matters are discussed.

The economics of developing and marketing GMOs is an important subject. It influences the type of GMO developed and market structures. These and related aspects are also discussed in Chapter 7. Other socioeconomic issues covered include patent protection and property rights in GMOs, the lack of biological and social co-evolution and different types of social conflicts arising from the use of GMOs, as well as problems posed by asymmetric information about GMOs. Before concluding Chapter 7, further assessment is undertaken of legal liability as a means of responding to any adverse consequences of the use of GMOs, such as negative environmental spillovers.

Chapter 8 explores the economic value of human developed and modified ecosystems. In the recent economic literature, the economic value of these has been neglected compared to consideration of the values of natural ecosystems. Reasons why this has happened are suggested. The 
various concepts of an ecosystem are outlined and their relevance to human developed ecosystems is examined. In addition, the dynamic properties of ecosystems are investigated, such as the nature of their resilience and their resistance to change.

Economic methods of valuing human developed and modified ecosystems are outlined and evaluated. The general environmental consequences of ecosystems altered by humans for cultivation purposes are identified, paying attention to onsite and offsite biotic and abiotic changes. A key component of this chapter is its assessment of the comparative economic value of alternative types of agroecosystems, as well as different forms of aquaculture and silviculture. Particular attention is given to evaluating high external resource-using agroecosystems and to the concept of sustainable agricultural intensification. The latter potential development is currently touted by many scholars as the ideal means to increase global food production at minimum (or even zero) economic cost and without loss of environmental quality. This view is examined critically.

In the following discussion, the prospects of utilizing increased intensification of bio-industries to increase food production and reduce their environmental footprint are investigated analytically. It is argued that although this win-win outcome may be possible, political and market failures can result in this outcome not being achieved. Furthermore, the evaluation of environmental change is usually ambiguous because it is normally the case that both positive and negative environmental changes occur when ecosystems are transformed. In most cases, it seems likely that intensification of ecosystems will have both positive and negative environmental effects and so their comparative net values will need to take this into account. Even changes which seem overall to be environmentally friendly are likely to have some negative environmental consequences.

In Chapter 7, the subject of the reduced biological fitness of organisms that have been genetically modified to resist pests and diseases is given attention. Chapter 9 further contributes to this subject by exploring the basic economics of evolutionary resistance to control techniques of pests and diseases. This resistance can develop for the use of a wide range of control techniques. These include controls based on the use of antibiotics, chemicals (such as herbicides), genetic modification to organisms, and even in the case of classical biological methods of pest control, as for example happened in Australia with the release of the myxomatosis virus to control Australia's population of rabbits.

A significant economic feature of the use of many techniques (which decline in their biological effectiveness for controlling pests or diseases as the frequency or duration of their use increases) is the failure of users 
to take into account the collective user cost of their use. This is the main subject investigated in Chapter 9.

It is shown that if the supply of this type of control method is available under conditions of pure competition, or is made available at the cost of supply by government (as has happened in some lower-income countries), this promotes its socially excessive (economic) use. The possibility that a monopoly would result in the efficient supply and use of such a technique is also investigated. It is shown that this is possible under special conditions. However, a monopolist substantially reduces the economic surplus of consumers (users) of the control technique. This can be excessively so from a social economic welfare point of view. On the other hand, this might be counterbalanced (in a dynamic setting) by a faster rate of technological progress under monopoly, if the theories of Clark (1940) and Schumpeter (1942) apply.

As part of the analysis in this chapter, the types of users that ought to be given priority in their access to techniques that decline in effectiveness with use are identified. The value judgement underlying this is that it ought to be based on willingness to pay. However, I would like to emphasize that this is a contentious assumption (but a standard one in economics) and is unlikely to have widespread community support in cases where the health and survival of individual human beings is at stake. Communal pressures are likely to exist to make these types of treatments available to (at least) some needy groups of individuals who are unable to pay for the cost of their provision, for example, by means of public health schemes subsidizing health treatment. Moreover, strong social pressures are likely to exist to allow greater current use of these techniques than is strictly optimal from an economics point of view. This is a fertile subject for further research.

From Chapter 9, it is apparent that property rights in much human developed genetic material play an important role in their development and in their sustainable use. Moreover, they can also be a significant influence on the conservation of existing human developed germplasm. Chapter 10 examines the economics of property rights in human developed genetic material, giving particular attention to relatively new institutional developments, such as plant variety rights and biopatenting. Furthermore, the consequences of contemporary legal developments, particularly international ones, are scrutinized in relation to this topic. These agreements include the International Convention on the Protection of New Variety of Plants (UPOV), the Convention on Biological Diversity, the Agreement on Trade-Related Aspects of Intellectual Property Rights (TRIPS) and the International Treaty on Plant and Genetic Resources for Food and Agriculture (ITPGFA). Some important inconsistencies between these agreements are identified, some of which can be attributed to what is 
described by Feindt (2012) as 'layering'. In addition, it is contended that these inconsistencies, as well as the vagueness of some clauses in these agreements, reflect international political and social conflicts.

\subsection{OVERVIEW OF PART III - WILD BIODIVERSITY AND NATURAL ECOSYSTEMS: MORE ECONOMIC ANALYSIS OF ECONOMIC ISSUES INVOLVED IN BIOLOGICAL CONSERVATION}

Whereas the main focus in Part II is on the economics of the conservation and loss of human developed germplasm and human modified ecosystems, the focus in Part III shifts to the economics of the conservation and the loss of wild biodiversity and natural ecosystems. Chapter 11 provides a general introduction to this part. It begins by pointing out the shortcomings of many economic studies which purport to analyse the economics of biodiversity conservation and loss. They actually fail to value diversity as such and consider only the economic value of particular natural objects, not their variety and the extent of their differences.

The economic valuation of the non-material benefits of the conservation of wild biodiversity is discussed and some empirical information is given about this. This is followed by consideration of the economics of the potential material benefits of wild biodiversity conservation, for example, its potential value for supplying pharmaceuticals.

It is important to take into account the total economic value of wild biodiversity and natural ecosystems. Some of the basic and little discussed problems (both empirical and philosophical) which arise in doing this are identified. Several divergent views exist about the comparative economic value of natural and modified ecosystems. For example, scholars differ in their views about the extent to which natural ecosystems can continue to be modified without reducing human well-being, and about relationships between the modifications to particular ecosystems and their impact on human welfare. These views are considered in Chapter 11.

Several important points are made in Chapter 11. For example, the importance of recognizing the relative nature of economic valuation and cost-effectiveness analysis as a basis for economic decision-making is emphasized. It shows that the economic value ascribed to a natural object may increase even though its degradation occurs. Moreover, the extent to which cost-effectiveness analysis can obviate the need for economic valuation is questioned.

Socio-economic reasons for socially detrimental alterations to natural ecosystems and biodiversity are identified. These are wide ranging in 
nature and include market failure, political problems, and shortcomings in public administration and in decision-making by NGOs. These are all discussed and analysed.

Several policy issues are raised by the coverage of the topic in Chapter 11. These are addressed in Section 11.10. It is pointed out that a wide range of different public policies are possible for influencing the conservation of biodiversity and the supply of ecosystem services. Payment for the supply of ecosystem services is just one possibility and may not always be the socially most desirable policy option. It is important to compare the social desirability of alternative policies and their sustainability, as becomes evident from some of the subsequent chapters, for instance, Chapter 16.

The main purpose of Chapter 12 is to demonstrate the importance of relative values in making decisions about land use in order to minimize the opportunity cost of conserving wild species in their natural habitats. Several authors (mostly ecologists) make the mistake that such decisions should be based on absolute values. For example, cases occur in the literature recommending that land areas which give the highest (absolute) returns to commercial use should be allocated to this purpose rather than to nature conservation, or that areas able to support the highest densities of the species to be conserved ought to be used for this purpose.

The conservation of the orangutan is taken as an example and both the private and social opportunity costs of its conservation are considered. It is assumed that a land-saving strategy rather than a land-sharing conservation strategy is adopted. However, in Chapter 17, the optimality of landsparing versus a land-sharing conservation strategy is considered. Once again, the conservation of the orangutan is used to illustrate this analysis.

Chapter 13 pays particular attention to the role which private property rights in wildlife can play (or fail to do so) in their conservation. It also discusses features of international agreements which affect trade in wildlife species or their parts, and consequently, the conservation of individual species of wildlife.

In examining the prospects of use of wildlife for conservation purposes while on a private landholding or on areas controlled by an NGO, the conservation consequences are considered of the landholder being able to extract non-consumptive use value, or alternatively, consumptive use value from this presence of wildlife. This is shown to be influenced by the mobility patterns of different wildlife species. Also in the case of highly mobile wildlife harvested for consumptive use, it is found that the private property solution results in a different outcome from the open-access one. This has not previously been made clear in the relevant literature.

The conservation consequences of often conflicting global rights to trade in wildlife and their parts are examined. Particular consideration 
is given to the differing approaches adopted in the Convention on International Trade in Endangered Species (CITES) and in the Convention on Biological Diversity (CBD).

Chapter 14 extends the discussion in Chapter 13. It does this by giving further attention to the conservation consequences of granting property rights in wildlife species to landholders when these species are present on their land. It also considers the effects of other economic incentives to conserve wildlife species on private lands. Its coverage includes economic analysis, policy issues and examples. After considering private property rights and free markets as a means for conserving wildlife and pointing out some limitations of this approach, it identifies a range of other economic policies which may be adopted by governments for conserving wildlife on private land. These alternative economic policies are assessed, and this is followed by further examination of some actual government scheme to provide economic incentives for the conservation of wildlife on private land.

The relatively radical thesis that there is no regular relationship between the level of the rate of interest and loss of wild species (also loss of natural capital) is developed in Chapter 15. The usual view presented in the economic literature is that an increase in the rate of interest increases the likelihood of extirpation of wild species. However, this is shown to be only true for some microeconomic situations. Furthermore, when account is taken of macroeconomic relationships, it is demonstrated that the abovementioned hypothesis does not hold. Taking into account macroeconomic relationships, increased loss of natural capital (and, therefore, greater loss of wild biodiversity) can occur, in some circumstances when the rate of interest falls, and in other cases when it rises.

This is because increases in the level of aggregate economic activity, and in the level of aggregate investment are the prime drivers of the loss of natural capital. These levels can be associated with either a rise or a fall in the rate of interest. In macroeconomic contexts, the rate of interest is a dependent variable not an independent one. Therefore, both on the basis of microeconomic and macroeconomic analysis, the definite conclusion is reached in Chapter 15 that there is no regular relationship between the loss of natural capital (and the decline in wild biodiversity) and the level of the rate of interest.

Processes involved in the economic valuation of natural ecosystems and their sustainability are the focus of Chapter 16. It begins with a discussion of the role of natural capital in influencing human well-being. It is pointed out that some recent models (for example, Costanza et al., 2014), which include natural capital as a contributor to human well-being, are too restrictive in their identification of contributors to human well-being. This 
is followed by critical observations on recent estimates of the global value of ecosystem services and a general discussion of alternative economic methods of valuing ecosystem services. The implications of some of these estimates are disturbing. Furthermore, most rely on a hodgepodge of data collected using different methods, some of which have been applied in a dubious manner, for example, the cost of replacement method. An important and interesting issue discussed is macroeconomic accounting for the value of ecosystem services versus microeconomic welfare accounting for their value.

Particular attention is given to the limitations of adopting cost-side methods of economic valuation of ecosystem services compared to demand-side valuation. Situations in which cost-side replacement valuation is an accurate indicator of economic value (and others in which it is not) are identified. Usually, both demand-side and cost-side factors need to be taken into account in economic valuation.

There is a danger when cost of replacement methods are used that existing ecosystem services will be overvalued. The cost of replacement methods never undervalue the loss of ecosystem services but very often overvalue them, as is demonstrated. This is followed by a discussion of the role of economics in the valuation of changes in ecosystems along with some illustrations involving the introduction of invasive (pests) species to new geographical regions, and the adoption of inappropriate methods of ecosystem 'restoration'. Taking China's Grain for Green Project as an example, for illustrative purposes, there is additional discussion (beyond that provided in Chapters 13 and 14) on the policy of paying landholders for the supply of ecosystem services. Attention is given to the potential consequences of the lack of permanency of such payments and to principal-agent problems associated with such payments.

The supply of ecosystem services and the economics of their provision depend on the spatial use of the biosphere by human beings. The economics of the spatial use of ecosystems are considered in Chapter 17 which, for analytical purposes, introduces a model which examines the economics of using a forest for wildlife conservation and for the supply of logs. The discussion is relevant to the debate about the desirability of land sharing versus land sparing as alternative means of conserving wild biodiversity and simultaneously meeting human demands on ecosystems (land use) for the supply of provisioning of services (such as timber and food). An aim of this chapter is to determine the optimal (economic) pattern of the use of a forested area that conserves a minimum viable population of a focal wildlife species and which (subject to this constraint) maximizes profit from logging. The model can also be applied if it is desired to conserve a higher targeted population of the focal species, thereby increasing the chances of 
its survival. Furthermore, it can be extended to include the conservation of more than a single species. However, when this is done, it usually imposes increased restrictions on forest operations (logging must be more selective) when the land-sharing option is considered. As a result, mixed land-use (land sharing) can be expected to become less profitable and so the probability of land sparing (spatial separation of the provision of ecosystems services) is likely to become more attractive.

The modelling is applied to the conservation of the orangutan. It therefore adds to the discussion in Chapter 13 about the conservation of the orangutan. Some dynamic spatial aspects of the recovery of the population of a wild species after its habitat has been disturbed are discussed. For example, the retention of nuclei of the wild population in small, fully conserved cells from which they can disperse as a forest recovers from logging.

The debate about the desirability of land sharing versus land sparing has mostly been conducted by ecologists. Most, however, do not specify the valuation functions that they have in mind. They are usually not made explicit. Therefore, it is not surprising that much of this debate is inconclusive. At the same time, it is clear from the analysis in Chapter 17 of this book (and elsewhere in this book) that social optimality of land sharing versus land sparing varies according to areal variations in economic and ecological (environmental) conditions. In addition, because there are many different forms of land sharing, it is also apparent that the optimal choice between land sharing and land sparing requires many different alternatives to be considered, not just two.

\subsection{CONCLUDING COMMENTS}

This book contains a constructively critical discussion of contemporary views about the economics of biodiversity conservation and the supply of ecosystem services. It also throws doubt on some propositions and policies for resource conservation that have been proposed by ecologists. It is important that the role of biodiversity conservation and the provision of ecosystem services for human well-being and for sustainable development be assessed from varied points of view, and that rational scepticism be exercised in doing so. Therefore, I present several perspectives which are at odds with mainstream contemporary views about biological conservation, where this seems to be warranted. 


\section{REFERENCES}

Clark, J.M. (1940), 'Towards a concept of workable competition', American Economic Review, 30, 241-56.

Conway, G.R. (1985), 'Agroecosystem analysis', Agricultural Administration, 20, $31-55$.

Conway, G.R. (1987), 'The properties of agroecosystems', Agricultural Systems, 24, 95-117.

Costanza, R., R. De Groot, P. Sutton, S. Van der Ploeg, S.J. Anderson, I. Kubiszewski, S. Farber and R.K. Turner (2014), 'Changes in the global value of ecosystem services', Global Environmental Change, 26, 152-8.

Daly, H.E. (1999), Ecological Economics and the Ecology of Economics: Essays in Criticism, Cheltenham, UK and Northampton, MA, USA: Edward Elgar Publishing.

Feindt, P.H. (2012), 'The politics of biopatents in food and agriculture, 1950-2010: Value conflict, competing paradigms and contested institutionalisation in multilevel governance', Policy and Society, 31, 281-93.

Gowdy, J. and L. Krall (2013), 'The ultrasocial origin of the Anthropocene', Ecological Economics, 95, 137-47.

Kumar, P. (ed.) (2010), The Economics of Ecosystems and Biodiversity: Ecological and Economic Foundations, London and Washington, DC: Earthscan.

Pearce, D.W. (1998), Economics and Environment: Essays on Ecological Economics and Sustainable Development, Cheltenham, UK and Northampton, MA, USA: Edward Elgar Publishing.

Schumpeter, J. (1942), Capitalism, Socialism and Democracy, 2nd edn, New York: Harper \& Brothers. 